\title{
Polymer Reactions of the Pendant Alkyl Bromides of Soluble and Insoluble Polyoxetanes for the Preparation of Chemically Modified Polyethers
}

\author{
Masatoshi MotoI, Hiroshi SudA, Masato KiJIMA, \\ Tetsuya DOI, Tsuyoshi NAKAGAWA, \\ and Shigeyoshi KANOH \\ Department of Chemistry and Chemical Engineering, \\ Faculty of Technology, Kanazawa University, \\ Kodatsuno, Kanazawa 920, Japan
}

(Received November 28, 1988)

\begin{abstract}
Soluble and insoluble polyoxetanes with $\omega$-brom-2-oxaalkyl side chains of $-\mathrm{CH}_{2} \mathrm{O}\left(\mathrm{CH}_{2}\right)_{n} \mathrm{Br}(n=4$ or 6$)$ were prepared by cationic ring-opening polymerization of $3-(\omega-$ bromo-2-oxaalkyl)-3-methyloxetanes and by their co- or terpolymerizations with other oxetanes and/or cross-linking agents such as bisoxetanes $\mathrm{X}-\mathrm{CH}_{2} \mathrm{O}\left(\mathrm{CH}_{2}\right)_{n} \mathrm{OCH}_{2}-\mathrm{X} \quad(\mathrm{X}=3$-methyl-3oxetanyl and $n=4$ or 6 ). The bromine at the 2-oxapolymethylene-spacer end of the soluble polymers were converted into the corresponding functional groups by polymer reactions with several nucleophiles such as anions of carboxylates and alkoxides, and amines. The pendant acetoxyl and cyclic acetal groups, thus introduced, were hydrolyzed to give the corresponding hydroxyl groups. Quaternization of the pendant bromides of the uncross- and cross-linked polyoxetanes took place with nicotinamide or tributylamine. The product polymers with a tetraalkylammonium moiety showed catalytic activity for a phase-transfer catalytic reaction of alcohols and alkyl bromides giving ether compounds in satisfactory yields. Electrophilic substitutions such as bromination, nitration, and acylation were examined in pendant aromatic rings of poly(3-benzyloxetane)s. The electrophilic substitutions occurred at 70 to $90 \%$, although some decrease in the molecular weight of the product polymer was observed owing to ether cleavage of the polymer chain under acidic conditions.

KEY WORDS Polymer Reactions / Cationic Ring-Opening Polymerization

/ Oxetane Derivatives / Uncross- and Cross-Linked Polyoxetanes / Alkyl

Bromides at Spacer End/
\end{abstract}

Chloromethylated cross-linked polystyrenes have widely been used as polymer supports in the synthesis of functional polymers. Although polystyrene supports are easily available, one has often encountered the drawbacks of hard, hydrophobic supports which are unfavorable for swelling in hydrophilic or polar solvents. On the other hand, most polyethers are wellknown to be soft and polar, because their ether groups are thought to possess several properties that the ethers with low molecular weights have in general. Especially, the polyoxiranes have often been employed as soft (or elas- tic),${ }^{1-3}$ polar, ${ }^{4-7}$ or hydrophilic ${ }^{8-10}$ segments in block- and graft-polymers, in which other segments are hard or less polar polymers such as polystyrenes, polyethylenes, and polyamides. In order to avoid disadvantages in using the hard, hydrophobic chloromethylated polystyrene supports in the polymer modification, we prepared soft, more polar polymer supports carrying pendant alkyl halides which are convertible into desired functional groups by proper polymer reactions; we found a facile preparation method of oxetane monomers with a terminal bromide in the side chain (3a 

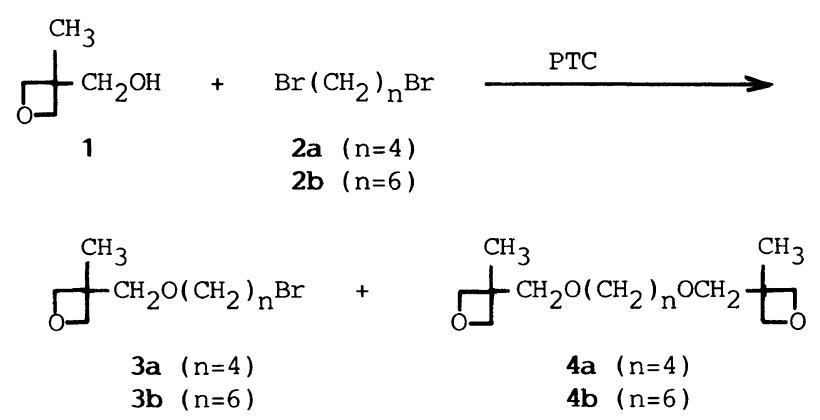

Scheme 1

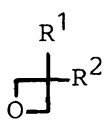

$7 \mathrm{R}^{1}=\mathrm{R}^{2}=\mathrm{CH}_{2} \mathrm{C}_{6} \mathrm{H}_{5}$

$8 \mathrm{R}^{1}=\mathrm{H}, \mathrm{R}^{2}=\mathrm{CH}_{2} \mathrm{C}_{6} \mathrm{H}_{5}$

$9 \mathrm{R}^{1}=\mathrm{CH}_{3}, \mathrm{R}^{2}=\mathrm{CH}_{2} \mathrm{C}_{6} \mathrm{H}_{5}$

$10 \mathrm{R}^{1}=\mathrm{CH}_{3}, \mathrm{R}^{2}=\mathrm{CH}_{2} \mathrm{C}_{6} \mathrm{H}_{4} \mathrm{Cl}-(\mathrm{p})$

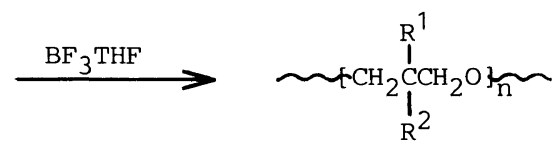

$\operatorname{poly}(7)-\operatorname{poly}(10)$

Scheme 2

and $\mathbf{3 b}$ ) and bifunctional oxetane derivatives (4a and $\mathbf{4 b}) .{ }^{11}$ These bisoxetanes were successfully used to give elastic polyoxetane resins with the bromide at the 2-oxapolymethylene spacer-end by cationic ring-opening copolymerization with $\mathbf{3 a}$ or $\mathbf{3 b}$. We have thus been interested in the investigation of the chemical reactions of the pendant alkyl bromide of the uncross- and cross-linked polyoxetanes to obtain various functionalized polyethers.

So far, polyoxetanes with various pendant functional groups have been prepared via the polymer reaction of poly[3,3-bis(chloromethyl)oxetane $]^{12}$ or the ring-opening polymerization of the oxetanes with alkoxyl, cyano, hydroxyl, and halo groups. ${ }^{13-16}$ Recent reports concerning hydroxy-substituted polyethers are interesting from the view point of hydrophilic polymers synthesis. ${ }^{17-19}$ Chlorine of poly(epichlorohydrin) was also used in polymer reactions to give the modified polyoxiranes. $^{20}$

In this paper, we report nucleophilic re- actions of bromide at the 2-oxapolymethylene spacer-end of soluble and insoluble polyoxetanes in order to prove its chemical reactivity in a preliminary investigation for preparing functionalized polyethers. In addition, oxetanes with benzyl groups at the C-3 position were also prepared to examine electrophilic displacement reactions of the pendant aromatic rings of the polyoxetanes obtained by the cationic ring-opening polymerization of the 3-benzyloxetanes.

\section{EXPERIMENTAL}

\section{Materials}

3-Hydroxymethyl-3-methyloxetane (1) ${ }^{21}$ oxetane (5), ${ }^{22}$ and 3,3-dimethyloxetane $(6)^{23}$ were prepared according to methods of the literature. The oxetane derivatives $\mathbf{3 a}, \mathbf{3 b}, \mathbf{4 a}$, and $4 \mathrm{~b}$ were prepared in $63-76 \%$ yield, following the method reported previously by us. ${ }^{11}$ Tetra- (2a) and hexamethylene dibromides (2b), benzyl alcohol (11), $N$-methyl- 
aniline (12), nicotinamide (13), potassium acetate (KOAc), tributylamine (14), and tetrabutylammonium bromide (TBAB) were of guaranteed grade and used without further purification. Dichloromethane (DCM) as a polymerization solvent was twice distilled over calcium hydride in an atmosphere of dry nitrogen. A boron trifluoride $\left(\mathrm{BF}_{3}\right)$-tetrahydrofuran (THF) complex was prepared by passing $\mathrm{BF}_{3}$ gas into dry $\mathrm{THF}^{24}$

3-(6-Acetoxy-2-oxahexyl)-3-methyloxetane (15). 3a $(84.4 \mathrm{mmol})$ was heated under reflux for $6 \mathrm{~h}$ with powdered KOAc $(0.28 \mathrm{~mol})$ in benzene $(50 \mathrm{ml})$ in the presence of TBAB $(4.3 \mathrm{mmol})$ with efficient stirring. An organic layer was washed with water and dried over $\mathrm{Na}_{2} \mathrm{SO}_{4}$. After removing the solvent, fractional distillation of the residue gave slightly impure 15 in about $84 \%$ yield: bp $107^{\circ} \mathrm{C}$ $(0.87 \mathrm{mmHg}$ ); IR (neat) 1745 (ester $\mathrm{C}=\mathrm{O})$, 1245 and 1040 (ester $\mathrm{C}-\mathrm{O}-\mathrm{C}$ ), 1110 (acyclic ether), and 980 and $830 \mathrm{~cm}^{-1}$ (cyclic ether); ${ }^{1} \mathrm{H}$ $\operatorname{NMR}\left(\mathrm{CDCl}_{3}\right) \delta 1.33\left(\mathrm{~s}, 3 \mathrm{H}, \mathrm{CH}_{3}\right), 1.48-1.90$ (m, 4H, OCH $\left.\mathrm{O}_{2}\left(\mathrm{CH}_{2}\right)_{2} \mathrm{CH}_{2} \mathrm{OAc}\right], 2.05$ (s, 3H, $\left.\mathrm{COCH}_{3}\right), 3.35-3.78$ [total $6 \mathrm{H}: \mathrm{m}, \mathrm{OCH}_{2}-$ $\left(\mathrm{CH}_{2}\right)_{2} \mathrm{CH}_{2} \mathrm{OAc} ; \mathrm{s}(\delta=3.49), \mathrm{CH}_{2}$ adjacent to oxetane ring], $4.13\left(\mathrm{t}, 2 \mathrm{H}, J=5.6 \mathrm{~Hz}, \mathrm{CH}_{2} \mathrm{O}-\right.$ $\mathrm{Ac}$ ), and 4.37 and $4.53 \mathrm{ppm}$ (each $2 \mathrm{H}$, each d, $J=6 \mathrm{~Hz}$, each proton of $\mathrm{CH}_{2}$ of oxetane ring); Anal. Calcd for $\mathrm{C}_{11} \mathrm{H}_{20} \mathrm{O}_{4}$ : C, $61.07 \%$; $\mathrm{H}, 9.34 \%$. Found: C, $60.56 \%$; H, 9.29\%.

3-(6-Benzyloxy-2-oxahexyl)-3-methyloxetane (16). A phase-transfer catalytic reaction of $3 \mathbf{a}(42.2 \mathrm{mmol})$ with $11(38.0 \mathrm{mmol})$ gave $\mathbf{1 6}$ in a $72.6 \%$ yield in the presence of $\mathrm{TBAB}$ $(1.9 \mathrm{mmol})$ in hexane $(40 \mathrm{ml})$ and $50 \% \mathrm{NaOH}$ $(50 \mathrm{~g})$ : bp $144.0-144.5^{\circ} \mathrm{C}(0.50 \mathrm{mmHg})$; IR (neat) 1605,1590 , and 1500 (aromatic $\mathrm{C}=\mathrm{C}$ ), 1110 (acyclic ether $\mathrm{C}-\mathrm{O}-\mathrm{C}$ ), 908 and 835 (cyclic ether), and 740 and $700 \mathrm{~cm}^{-1}$ (monosubstituted aromatic ring); ${ }^{1} \mathrm{H}$ NMR $\left(\mathrm{CDCl}_{3}\right) \delta$ $1.28\left(\mathrm{~s}, 3 \mathrm{H}, \mathrm{CH}_{3}\right), 1.47-1.97\left[\mathrm{~m}, 4 \mathrm{H}, \mathrm{OCH}_{2}-\right.$ $\left(\mathrm{CH}_{2}\right)_{2} \mathrm{CH}_{2} \mathrm{O}$ ], 3.29-2.71 [total 6H: m, $\mathrm{OCH}_{2}-$ $\left(\mathrm{CH}_{2}\right)_{2} \mathrm{C}_{2} \mathrm{O} ; \mathrm{s}(\delta=3.43), \mathrm{CH}_{2}$ adjacent to oxetane ring], 4.23-4.65 [total $6 \mathrm{H}: \mathrm{s}(\delta=$ 4.49), $\mathrm{CH}_{2} \mathrm{Ph}$; each $\mathrm{d}(\delta=4.31$ and 4.49$), J=$
$5.5 \mathrm{~Hz}, \mathrm{CH}_{2}$ of oxetane ring], and $7.25-7.50$ ppm (5H, ArH).

Anal. Calcd for $\mathrm{C}_{16} \mathrm{H}_{24} \mathrm{O}_{3}: \mathrm{C}, 72.68 \% ; \mathrm{H}$, $9.17 \%$. Found: C, $72.73 \%$; H, 9.39\%.

5-Hydroxymethyl-2,2,5-trimethyl-1,3-dioxane (17). Cyclic acetal 17 was prepared in a $83.9 \%$ yield from 2-hydroxymethyl-2-methyl1,3 -propanediol $(0.55 \mathrm{mmol})$ and acetone $(2.05 \mathrm{~mol})$ using $p$-toluenesulfonic acid as an acid catalyst according to the preparation method of the corresponding 1,3-dioxolane ${ }^{25}$ : bp $72-73 \mathrm{C}(0.59 \mathrm{mmHg})$; IR (neat) 3450 (alcohol $\mathrm{OH}$ ), 1080 and 825 (acetal), and 1040 $\mathrm{cm}^{-1}$ (alcohol C-O-C); ${ }^{1} \mathrm{H}$ NMR $\left(\mathrm{CDCl}_{3}\right)$ $\delta 0.81\left(\mathrm{~s}, 3 \mathrm{H}\right.$, ungeminal $\left.\mathrm{CH}_{3}\right), 1.38$ and 1.41 (total $6 \mathrm{H}$, each $\mathrm{s}$, geminal $\mathrm{CH}_{3}$ ), 3.06-3.38 (br, $1 \mathrm{H}, \mathrm{OH}$ ), and $3.38-3.90 \mathrm{ppm}$ [total $6 \mathrm{H}$ : s $(\delta=3.61), \mathrm{C}_{2} \mathrm{OH}$; triplet-like $(\delta=3.61), J=$ $12 \mathrm{~Hz}, \mathrm{CH}_{2}$ of acetal ring].

5-(2-Oxahexyl)-2,2,5-trimethyl-1,3-dioxane (18). This was prepared in a $81.8 \%$ yield by the phase-transfer catalytic reaction of 17 (31.2 mmol) with butyl bromide $(93.6 \mathrm{mmol})$ in the presence of TBAB $(1.56 \mathrm{mmol})$ in hexane $(50 \mathrm{ml})$ and a $50 \% \mathrm{NaOH}$ solution $(42 \mathrm{~g})$ : bp $109-110^{\circ} \mathrm{C}(12 \mathrm{mmHg})$; IR (neat) 1115 (acyclic ether), and 1090 and $835 \mathrm{~cm}^{-1}$ (acetal); ${ }^{1} \mathrm{H}-\mathrm{NMR}\left(\mathrm{CDCl}_{3}\right) \delta 0.66-1.17$ [total $6 \mathrm{H}: \mathrm{CH}_{3}$ of butyl; s $(\delta=0.89)$, ungeminal $\left.\mathrm{CH}_{3}\right], 1.17-$ 1.80 [total $10 \mathrm{H}: \mathrm{m}, \mathrm{CH}_{2} \mathrm{CH}_{2} \mathrm{CH}_{2} \mathrm{CH}_{3}$; s $(\delta=$ 1.42), geminal $\mathrm{CH}_{3}$, and $3.20-3.92 \mathrm{ppm}$ [total $8 \mathrm{H}: \mathrm{s}(\delta=3.40), \mathrm{CH}_{2}$ adjacent to acetal ring; $\mathrm{t}(\delta=3.44), \quad J=6 \mathrm{~Hz}, \mathrm{OCH}_{2} \mathrm{CH}_{2} \mathrm{CH}_{2}-$ $\mathrm{CH}_{3} ; 2 \times \mathrm{d}(\delta=3.54$ and 3.72$), J=11.2 \mathrm{~Hz}$, each proton of $\mathrm{CH}_{2}$ of acetal ring].

Anal. Calcd for $\mathrm{C}_{12} \mathrm{H}_{24} \mathrm{O}_{3}: \mathrm{C}, 66.61 \% ; \mathrm{H}$, $11.20 \%$. Found: $\mathrm{C}, 66.42 \%$; H, $11.45 \%$.

Preparation of 3-Benzyloxyetanes 7, 8, 9, and 10. Diethyl benzyl-, dibenzyl-, and benzylmethyl-malonates were prepared according to the methods of the literatures. ${ }^{26-28}$ These esters $(0.15 \mathrm{~mol})$ dissolved in dry ether $(400$ $\mathrm{ml})$ were reduced in yields of $73-88 \%$ to the corresponding 1,3-propanediols by adding a suspension of lithium aluminum hydride (LAH) $(0.28 \mathrm{~mol})$ in dry ether $(80 \mathrm{ml})$ into the 
ester below $5{ }^{\circ} \mathrm{C}$ with stirring. The resultant diols were converted into the corresponding 3chloropropyl acetates in yields of $80-87 \%$ by heating an equimolar mixture of the diol and acetyl chloride in a sealed tube at $140^{\circ} \mathrm{C}$ for $9 \mathrm{~h}$. The 3-chloropropyl acetates gave $8(60 \%)$, $9(17 \%)$, or $10(16 \%)$ on treatment of the ester with hot concentrated alkaline solution according to the method reported by Rose. ${ }^{22} 7$ was obtained in a $80 \%$ yield from 2,2-dibenzyl1,3-propanediol in a similar manner as described by Moulines. ${ }^{29}$

3,3-Dibenzyloxetane (7): bp $145-155^{\circ} \mathrm{C}$ $(1 \mathrm{mmHg})\left[\mathrm{lit}^{30} 135^{\circ} \mathrm{C}(0.1 \mathrm{mmHg})\right]$; IR (neat) $3060,3030,1600,1580,1497$, and 1450 (aromatic ring), 980 and 835 (cyclic ether), and 750 and $700 \mathrm{~cm}^{-1}$ (monosubstituted aromatic ring); ${ }^{1} \mathrm{H}-\mathrm{NMR} \quad\left(\mathrm{CDCl}_{3}\right) \quad \delta 2.34 \quad(\mathrm{~s}, \quad 4 \mathrm{H}$, $\left.\mathrm{CH}_{2} \mathrm{Ph}\right), 4.47\left(\mathrm{~s}, 4 \mathrm{H}, \mathrm{CH}_{2}\right.$ of oxetane ring), and $6.84-7.39 \mathrm{ppm}(\mathrm{m}, 10 \mathrm{H}, \mathrm{ArH})$.

3-Benzyloxetane (8): bp $107.0-109.8^{\circ} \mathrm{C}$ $(16-18 \mathrm{mmHg})\left[\mathrm{lit}^{31} 105-110^{\circ} \mathrm{C}(4 \mathrm{mmHg})\right]$; IR (neat) 3050, 3020, 1600, 1490, 970, 850, 720, and $690 \mathrm{~cm}^{-1} ;{ }^{1} \mathrm{H} \mathrm{NMR}\left(\mathrm{CDCl}_{3}\right) \delta 2.90-3.60$ (total $3 \mathrm{H}$ : $\mathrm{m}, \mathrm{CH}_{2} \mathrm{Ph}$ and $\mathrm{CH}$ on $\mathrm{C}-3$ of oxetane), $4.35-4.98\left(4 \mathrm{H}, \mathrm{m}, \mathrm{CH}_{2}\right.$ of oxetane ring), and 7.02-7.42 ppm (m, 5H, ArH).

3-Benzyl-3-methyloxetane (9): bp 109.0$110.5^{\circ} \mathrm{C}(19 \mathrm{mmHg})$; IR (neat) 3070,3040 , 1630, 1500, 980, 835, 755, and $705 \mathrm{~cm}^{-1} ;{ }^{1} \mathrm{H}$ NMR $\left(\mathrm{CDCl}_{3}\right) \delta: 1.26\left(\mathrm{~s}, 3 \mathrm{H}, \mathrm{CH}_{3}\right), 2.93(\mathrm{~s}$, $2 \mathrm{H}, \mathrm{CH}_{2} \mathrm{Ph}$ ), 4.33 and 4.63 (each d, each $2 \mathrm{H}$, $J=5.7 \mathrm{~Hz}, \mathrm{CH}_{2}$ of oxetane ring), and 6.08 $7.50 \mathrm{ppm}(\mathrm{m}, 5 \mathrm{H}, \mathrm{ArH})$.

Anal. Calcd for $\mathrm{C}_{11} \mathrm{H}_{14} \mathrm{O}: \mathrm{C}, 81.44 \% ; \mathrm{H}$, $8.70 \%$. Found: C, $81.29 \%$; H, $8.79 \%$.

3-(4-Chlorobenzyl)-3-methyloxetane (10): bp $142-145^{\circ} \mathrm{C}(25 \mathrm{mmHg})$; IR (neat) 3030 , $1595,1495,1450,980,830$, and $795 \mathrm{~cm}^{-1} ;{ }^{1} \mathrm{H}$ NMR $\left(\mathrm{CDCl}_{3}\right) \delta 1.25\left(\mathrm{~s}, 3 \mathrm{H}, \mathrm{CH}_{3}\right), 1.41(\mathrm{~s}$, $2 \mathrm{H}, \mathrm{CH}_{2} \mathrm{Ar}$ ), 4.33 and 4.59 (each d, each $2 \mathrm{H}$, $J=6 \mathrm{~Hz}, \mathrm{CH}_{2}$ of oxetane ring), and $6.90-7.44$ ppm (m, 4H, ArH).

Anal. Calcd for $\mathrm{C}_{11} \mathrm{H}_{13} \mathrm{ClO}: \mathrm{C}, 67.18 \%$; $6.66 \% ; \mathrm{Cl}, 18.03 \%$. Found: C, $67.10 \% ; \mathrm{H}$, $6.71 \%, \mathrm{Cl}, 17.95 \%$.

\section{Cationic Ring-Opening Polymerization of} Oxetane Monomers

In a ground-glass test tube, dried and flushed with dry nitrogen gas, the oxetanes were placed by a hypodermic injection under a nitrogen atmosphere. The monomers were diluted with DCM, chilled at $-50^{\circ} \mathrm{C}$, and mixed with a catalytic amount of a $0.5 \mathrm{moll}^{-1}$ $\mathrm{BF}_{3} \mathrm{THF}$ solution in DCM. The test tube was closed by a ground-glass stopper and allowed to stand for $20 \mathrm{~h}$ in an ice bath. Soluble polymers were poured into methanol to precipitate viscous oily materials or flakes. Gel polymers were filtered and washed successively with $10 \%$ aqueous methanol and methanol. The polymers were collected and dried at $80^{\circ} \mathrm{C}$ for $8 \mathrm{~h}$ in vacuo.

Polymer Reactions of Polyoxetane Side Chains Reactions of the Pendant Bromides with KOAc: Typical Procedure. Poly(3a) $(0.70 \mathrm{~g}$, $2.95 \mathrm{mmol}$ of $\mathrm{Br}$ ) was dissolved in toluene $(13 \mathrm{ml})$ and stirred with powdered KOAc $(4.9 \mathrm{~g}, 50 \mathrm{mmol})$ under reflux for $24 \mathrm{~h}$ in the presence of TBAB $(0.15 \mathrm{mmol})$. The cooled contents were shaken with water. The organic layer was separated, concentrated, and poured into methanol to precipitate the product polymer. After being dried at $80^{\circ} \mathrm{C}$ in vacuo, 0.55 $\mathrm{g}$ of the product polymer was obtained.

Hydrolysis of the Pendant Acetate: Typical Procedure. Poly (15) (1.0 g) was heated with 2.5 moll $1^{-1}$ aqueous $\mathrm{NaOH}(9 \mathrm{ml})$ and methanol $(15 \mathrm{ml})$ at $60-70^{\circ} \mathrm{C}$ for $1 \mathrm{~h}$. At this time, the polymer dissolved completely in the solvent. Methanol was evaporated, and the residue was washed thoroughly with water and dried in vacuo to give $0.72 \mathrm{~g}(89 \%)$ of the product polymer, which indicated no IR bands due to the ester group.

Reactions of the Pendant Bromides with 11 and 17: Typical Procedure. Poly(3a) $(0.64 \mathrm{~g}$, $2.70 \mathrm{mmol}$ of $\mathrm{Br}$ ) was allowed to react with $\mathbf{1 1}$ $(1.4 \mathrm{~g}, 13.5 \mathrm{mmol})$ in ether $(29 \mathrm{ml})$ and a $50 \%$ $\mathrm{NaOH}$ solution $(5.0 \mathrm{~g})$ at reflux temperature for $16 \mathrm{~h}$ in the presence of TBAB $(0.15 \mathrm{mmol})$. 
The organic layer was washed with water, concentrated and poured into methanol. The precipitate was collected by decantation and dried in vacuo to give $0.71 \mathrm{~g}$ of the product polymer.

Reaction of Pendant Bromides with 12: Typical Procedure. Poly(3a-co-6) (0.78 g, 1.96 $\mathrm{mmol}$ of $\mathrm{Br})$ was heated with $12(0.42 \mathrm{~g}, 3.92$ mmol) in $15 \mathrm{ml}$ of $N, N$-dimethylformamide (DMF) at $60^{\circ} \mathrm{C}$ for $16 \mathrm{~h}$. The mixture was concentrated and poured into methanol. The precipitate was separated from the supernatant and reprecipitated by a chloroform-methanol system to give $0.61 \mathrm{~g}$ of the product polymer.

Reaction of Pendant Bromides with 13. Poly(3a) $(0.66 \mathrm{~g}, 2.78 \mathrm{mmol}$ of $\mathrm{Br})$ was heated with 13 (1.1 g, $9.2 \mathrm{mmol})$ in DMF $(20 \mathrm{ml})$ at $100^{\circ} \mathrm{C}$ for $15 \mathrm{~h}$. After removing the solvent by evaporation, the residue was dissolved in methanol and poured into ether. The precipitate was purified by reprecipitation using a methanol-acetone system to give the product polymer (1.2 g): Anal. Found: N, 6.94\%; Br, $18.48 \%$. To the product polymer $(50 \mathrm{mg})$ dissolved in methanol $(2 \mathrm{ml})$ was added a solution of $\mathrm{Na}_{2} \mathrm{~S}_{2} \mathrm{O}_{4} \quad(400 \mathrm{mg})$ and $\mathrm{K}_{2} \mathrm{CO}_{3}$ $(100 \mathrm{mg})$ in water $(1 \mathrm{ml})$ under a nitrogen atmosphere and the reduced polymer was deposited within a few minutes. The precipitate was filtered, washed with water, and dried in vacuo.

Quaternization of the Pendant Bromides of Cross-Linked Polyoxetanes with 14. Poly(3aco-4a) and poly (3b-co-4b) were each allowed to react with a threefold molar excess of $\mathbf{1 4}$ in $\mathrm{DMF}$ at $100^{\circ} \mathrm{C}$ for $15 \mathrm{~h}$. The polymer was filtered, washed with $10 \%$ aqueous methanol, methanol, and ether successively, and dried at $80^{\circ} \mathrm{C}$ for $6 \mathrm{~h}$ in vavuo. Anal. Found: N, $1.50 \%$; $\mathrm{Br}, 12.03 \%$ for $28 \mathrm{a}$ and $\mathrm{N}, 1.70 \%$, Br, $10.72 \%$ for $\mathbf{2 8 b}$.

Phase-Transfer Catalytic Reaction Between 1 and 2a in the Presence of a Polymeric PTC. In a test tube $(25 \phi \times 180)$, were placed a polymeric PTC (about 3\% molar respect to 1), 1 $(1.99 \mathrm{mmol}), \quad 2 \mathrm{a}(5.98 \mathrm{mmol})$, hexadecane
$(1.07 \mathrm{mmol})$ as an internal standard of gas chromatography (GLPC) analysis, and hexane $(2 \mathrm{ml})$. The contents in the test tube were cooled in an ice bath to charge $2.8 \mathrm{~g}$ of $50 \%$ $\mathrm{NaOH}$, and then heated under reflux with efficient stirring by a magnetic bar. At specified times, aliquots of a cooled organic layer were drawn into a microsyringe to determine the yields of 3a and $\mathbf{4 a}$ by GLPC.

Bromination of Poly(3-benzyloxetanes): Typical Procedure. Poly $(8)(0.47 \mathrm{~g}, 3.17 \mathrm{mmol}$ of benzyl group) dissolved in chloroform $(10 \mathrm{ml})$ was cooled at $0^{\circ} \mathrm{C}$ and allowed to react in the presence of $\mathrm{ZnCl}_{2}(0.45 \mathrm{~g}, 3.3 \mathrm{mmol})$ by the dropwise addition of bromine $(1.42 \mathrm{~g}$, $7.8 \mathrm{mmol})$ in chloroform $(5 \mathrm{ml})$. After adding the bromine solution, the mixture was stirred at room temperature in the dark for $21 \mathrm{~h}$. The mixture was poured onto crushed ice and neutralized with $\mathrm{NaOH}$. Excess of the bromine was treated with $\mathrm{Na}_{2} \mathrm{~S}_{2} \mathrm{O}_{3}$. The organic layer was washed with water, concentrated, and poured into methanol to precipitate the product polymer, which was dried at $60^{\circ} \mathrm{C}$ in vacuo. Anal. Found: Br, $25.60 \%$ and $26.37 \%$ for 29 and 31, respectively.

Nitration of Poly(9). Into a solution of poly $(9)(0.14 \mathrm{~g}, 0.86 \mathrm{mmol}$ of aromatic ring $)$ in chloroform $(8 \mathrm{ml})$, a mixture of $70 \%$ nitric acid $(0.5 \mathrm{ml}, \quad 7.9 \mathrm{mmol})$ and acetic anhydride $(2.0 \mathrm{mmol})$ was added slowly below $0^{\circ} \mathrm{C}$. After being stirred at 0 to $5^{\circ} \mathrm{C}$ for $10 \mathrm{~h}$, the reaction mixture was poured onto crushed ice and extracted with chloroform. Ordinary work-up of the organic layer gave a product polymer $(0.23 \mathrm{~g})$ : Anal. Found: N, $6.13 \%$. The nitrated polymer $(0.19 \mathrm{~g})$, reprecipitated by a chloroform-methanol system, was dissolved in dioxane $(10 \mathrm{ml})$ and mixed with $\mathrm{SnCl}_{2} \cdot 2 \mathrm{H}_{2} \mathrm{O}$ $(0.72 \mathrm{~g})$ and concd $\mathrm{HCl}(2.8 \mathrm{ml})$ at $50^{\circ} \mathrm{C}$ for $6 \mathrm{~h}$. The mixture was poured into cold water, made strongly basic, and extracted with ether. The organic layer was concentrated and poured into methanol to give a reduced polymer $(54 \mathrm{mg})$. The supernatant was concentrated and the residue was added to cold concd $\mathrm{HCl}$. 
The precipitate of the polymeric ammonium salt $(57 \mathrm{mg})$ was collected and washed with ether.

Acetylation of Poly(7). Into a solution of anhydrous $\mathrm{AlCl}_{3}(2.1 \mathrm{~g}, 15 \mathrm{mmol})$ in carbon disulfide $(10 \mathrm{ml})$, poly(7) $(1.65 \mathrm{~g}, 13.84 \mathrm{mmol}$ of aromatic ring) dissolved in the same solvent $(5 \mathrm{ml})$ was added. The mixture was stirred at reflux temperature for $48 \mathrm{~h}$ and then poured onto ice containing concd $\mathrm{HCl}$. Oily materials were extracted with DCM, concentrated, and poured into methanol to give a product polymer $(1.52 \mathrm{~g})$. The acylated polymer $(0.20 \mathrm{~g})$ was dissolved in pyridine $(10 \mathrm{ml})$ and allowed to react with hydroxylamine hydrochloride $(0.5 \mathrm{~g}, 4.8 \mathrm{mmol})$ at $90^{\circ} \mathrm{C}$ for $8 \mathrm{~h}$. The solvent was evaporated and the residue was poured into $.20 \%$ aqueous methanol to precipitate the oxime-containing polymer $(0.17 \mathrm{~g})$ : Anal. Found: N, $6.47 \%$.

\section{Measurement}

GLPC analysis of the products was performed by a Shimadzu GC-8A apparatus: glass colum $(3.2 \phi \times 1 \mathrm{~m})$ packed with Silicone High Vaccum Grease $(30 \%)$ /Celite (80-100 mesh); carrier gas, $\mathrm{He}\left(66 \mathrm{ml} \mathrm{min}^{-1}\right)$; temp, $200^{\circ} \mathrm{C}$. The IR spectra were recorded on a JASCO A202 spectrometer and ${ }^{1} \mathrm{H}$ NMR on a $60 \mathrm{MHz}$ instrument (Hitachi R-24B) using TMS as an internal standard. Molecular weight measurement was made by VPO in a Corona molecular weight apparatus (model 117).

\section{RESULTS AND DISCUSSION}

The monomers containing the bromine at spacer-ends, 3a and $\mathbf{3 b}$, were synthesized from 1 and threefold molar equivalents of $\alpha, \omega$ dibromoalkanes by a convenient method using $\mathrm{TBAB}$ as a $\mathrm{PTC}$ in hexane and a $50 \%$ aqueous

Table I. Cationic ring-opening polymerization of oxetanes in $\mathrm{DCM}$ at $0^{\circ} \mathrm{C}$ with $\mathrm{BF}_{3} \mathrm{THF}$

\begin{tabular}{|c|c|c|c|c|c|}
\hline \multirow{2}{*}{$\frac{\text { Monomer }}{\text { (Mole fraction) }}$} & \multirow{2}{*}{$\frac{[\mathrm{M}]_{0}{ }^{\mathrm{a}}}{\mathrm{mol} \mathrm{l}^{-1}}$} & \multicolumn{4}{|c|}{ Polymer } \\
\hline & & Name $^{b}$ & Yield $/ w t \%$ & Form & $10^{-3} \bar{M}_{n}^{\mathrm{c}}$ \\
\hline $\mathbf{3 a}$ & 2.6 & Poly (3a) & 91.9 & Oil & 5.5 \\
\hline $3 \mathbf{a}+\mathbf{6} \quad(35: 65)$ & 3.2 & Poly $(3 \mathbf{a}-c o-6)$ & 91.0 & Oil & 8.4 \\
\hline $3 \mathbf{a}+7 \quad(61: 39)$ & 4.3 & $\operatorname{Poly}(3 \mathrm{a}-\mathrm{co}-7)$ & 95.3 & Oil & n.d. ${ }^{d}$ \\
\hline $\mathbf{3 a}+\mathbf{4 a}(70: 30)$ & 2.3 & $\operatorname{Poly}(3 \mathbf{a}-c o-4 a)$ & 94.5 & Gel & \\
\hline $\begin{aligned} & 3 \mathbf{a}+\mathbf{6}+ \mathbf{4 a} \\
&(48: 42: 10)\end{aligned}$ & 2.5 & & $c a .100$ & Gel & \\
\hline $\mathbf{4 a}$ & 2.2 & & 86.5 & Gel & \\
\hline $\mathbf{3 b}$ & 2.4 & & 85.6 & Oil & 3.5 \\
\hline $\mathbf{3 b}+\mathbf{4 b}(79: 21)$ & 1.8 & $\operatorname{Poly}(3 \mathbf{b}-c o-4 b)$ & 98.5 & Gel & \\
\hline $5+\mathbf{4 b}(68: 32)$ & 3.8 & & 84.2 & Gel & \\
\hline $4 \mathrm{~b}$ & 2.3 & & 87.7 & Gel & \\
\hline 15 & 2.4 & Poly $(15)$ & 52.3 & Oil & 16.4 \\
\hline $15+4 a(80: 20)$ & 1.3 & Poly (15-co-4a) & 93.8 & Gel & \\
\hline 16 & 2.1 & Poly $(16)$ & 78.9 & Oil & 2.2 \\
\hline 7 & 1.7 & $\operatorname{Poly}(7)$ & 100.0 & Flakes & 9.8 \\
\hline 8 & 1.7 & Poly (8) & 91.0 & Oil & 2.0 \\
\hline 9 & 1.7 & Poly(9) & 100.0 & Flakes & 4.3 \\
\hline 10 & 1.7 & Poly(10) & 91.4 & Flakes & 3.8 \\
\hline
\end{tabular}

a Total monomer concentration at the beginning of polymerization.

b Names are given only for the polymers used in the polymer reactions described in this text. Monomeric unit composition of a copolymer is considered to be nearly equal to a mole ratio of the charged monomers (also see the text).

c For methanol-insoluble parts by VPO in acetone.

d Not determined. 
$\mathrm{NaOH}$ solution. The cross-linking agents, $4 a$ and $\mathbf{4 b}$, were also obtained by equimolar reaction between $\mathbf{1}$ and an appropriate dibromide under phase-transfer catalytic conditions. On the other hand, 6 and 7 were employed for comonomers in the polymerization with $\mathbf{3 a}$. Cationic ring-opening polymerizations of oxetanes were carried out in DCM at $0^{\circ} \mathrm{C}$ with $\mathrm{BF}_{3} \mathrm{THF}$ complex as an initiator. The results and conditions are summarized in Table I. 3a was polymerized to give a viscous oily product with a molecular weight of $5.5 \times 10^{3}$ by cationic ring-opening polymerization, $\operatorname{Poly}(\mathbf{3 a})$ obtained was soluble in DCM, chloroform, ether, benzene, acetone, and DMF. 3a, 4a, and $\mathbf{4 b}$ were polymerized in the same way as above.
Each of the latter two monomers gave a gel polymer, which was insoluble in the usual solvents, in its homo- and copolymerizations with other oxetanes. The IR bands at 980 and $835 \mathrm{~cm}^{-1}$ due to the ether linkage of the oxetane ring of $\mathbf{3 a}$ and $\mathbf{4 a}$ disappeared in the spectrum of poly(3a-co-4a), in which a strong band due to the acyclic ether linkage of the resultant polyether chain appeared at 1120 $\mathrm{cm}^{-1}$. Methylene protons of the oxetane ring of the monomers showed signals of an $\mathrm{AB}$ quartet pattern in $3.4-4.6 \mathrm{ppm}$ in the ${ }^{1} \mathrm{H}$ NMR spectra, but these signals disappeared in the spectra of the polymers. ${ }^{11}$ These findings indicate that almost all the monomers used were converted to their polyethers in spite of

Table II. Nucleophilic and electrophilic substitution reactions of pendant substrates of polyoxetanes

\begin{tabular}{|c|c|c|c|c|c|c|}
\hline \multirow[b]{2}{*}{ Entry } & \multicolumn{2}{|c|}{ Starting polymer } & \multirow[b]{2}{*}{ Reagent } & \multicolumn{3}{|c|}{ Product polymer } \\
\hline & & $\mathrm{g}(\mathrm{mmol})^{\mathrm{a}}$ & & Name & $\begin{array}{l}\text { D.F. }{ }^{b} / \% \\
\text { (Method) }^{\text {d }}\end{array}$ & $\begin{array}{l}\text { Yield }^{\mathrm{c}} / \\
\mathrm{g}(\%)\end{array}$ \\
\hline 1 & Poly(3a) & $0.70(2.95)$ & $\mathrm{KOAc} / \mathrm{TBAB}$ & 19 & $100(\mathrm{~A})$ & $0.60(94)$ \\
\hline 2 & Poly (3a-co-7) & $0.50(1.28)$ & $\mathrm{KOAc} / \mathrm{TBAB}$ & 20 & 97 (A) & $0.50(\mathrm{ca} .100)$ \\
\hline 3 & Poly(3a) & $0.64(2.70)$ & 11/TBAB & 22 & $100(\mathrm{~A})$ & $0.71(100)$ \\
\hline 4 & Poly(3a) & $0.41(1.37)$ & 17/TBAB & 23 & n.d..$^{\mathrm{e}}$ & $0.26-$ \\
\hline 5 & Poly(3a) & $0.67(2.83)$ & $12 / \mathrm{K}_{2} \mathrm{CO}_{3}$ & 25 & $100(\mathrm{~A})$ & $0.60(81)$ \\
\hline 6 & Poly (3a-co-6) & $0.78(1.96)$ & 12 & 26 & $60(\mathrm{~A})$ & $0.16(75)$ \\
\hline 7 & $\operatorname{Poly}(3 \mathbf{a})$ & $0.66(2.78)$ & 13 & 27 & $100(\mathrm{~A}, \mathrm{~B})$ & $1.02(c a .100)$ \\
\hline 8 & $\operatorname{Poly}(3 \mathbf{a}-c o-4 \mathbf{a})$ & $1.00(2.87)$ & 14 & 28a & $71(\mathrm{~B})$ & $1.09(55)$ \\
\hline 9 & $\operatorname{Poly}(\mathbf{3 b}-\mathrm{co}-\mathbf{4 b})$ & $1.16(3.40)$ & 14 & $28 b$ & 90 (B) & $1.26(51)$ \\
\hline 10 & Poly(7) & $0.55(4.62)$ & $\mathrm{Br}_{2} / \mathrm{ZnCl}_{2}$ & 29 & $51(\mathrm{~B})$ & $0.46(71)$ \\
\hline 11 & Poly $(8)$ & $0.47(3.17)$ & $\mathrm{Br}_{2} / \mathrm{ZnCl}_{2}$ & 30 & n.d. ${ }^{\mathrm{e}}$ & $0.64-$ \\
\hline 12 & Poly(9) & $0.19(1.17)$ & $\mathrm{Br}_{2} / \mathrm{ZnCl}_{2}$ & 31 & $72(B)^{f}$ & $0.19(74)$ \\
\hline 13 & Poly(9) & $0.14(0.86)$ & $\mathrm{HNO}_{3} / \mathrm{Ac}_{2} \mathrm{O}$ & 32 & $88(B)^{g}$ & $0.23^{\mathrm{h}}-$ \\
\hline 14 & Poly(7) & $1.65(13.84)$ & $\mathrm{AcCl} / \mathrm{AlCl}_{3}$ & 34 & $75(B)^{i}$ & $1.52(99)$ \\
\hline
\end{tabular}

a Values in parentheses indicate mmoles for the pendant substrates in the polyoxetanes.

b Degree of functionalization.

c Values in parentheses show yields in percentage based on theoretical amounts of the product polymers with the indicated D.F. In the calculation of yields, it was assumed that the mole fraction of a monomeric unit in the starting copolymer was identical with the mole fraction of the monomer fed in the copolymerization.

${ }^{d}$ D. F. was calculated by the following methods: (A) ${ }^{1} \mathrm{H}$ NMR spectroscopy: (B) elemental analysis for bromine and/or nitrogen.

e Not determined.

f $\bar{M}_{n}, 2300$.

g $\bar{M}_{n}, 1100$.

h This weight of the product polymer is heavier by about $30 \%$ than the theoretically calculated weight.

i D.F. was calculated on the basis of the nitrogen content of the oxime 35 derived from 34 in a quantitative conversion of its carbonyl group into the corresponding oxime group. 
forming very viscous or solid-like gel products in the polymerization. Formation of the copolymer was evident from easy dissolution of poly $\left(3 \mathbf{a}-c_{0}-\mathbf{6}\right)$ in the usual solvents, because the homopolymer of $\mathbf{6}$ was confirmed to be insoluble in the above solvents. Poly(3a-co-7) was soluble in the usual solvents examined but not clearly soluble in acetone below room temperature. Mole fractions of the monomeric units in a copolymer are considered to be almost identical with mole fractions of the monomers charged in their copolymerization, since the copolymer was obtained in a considerable high yield and unreacted monomers were hardly detected by GLPC analysis for a filtrate of the reprecipitation in polymer purification.
Nucleophilic Substitution Reactions of the Pendant Alkyl Bromides at the Spacer-End

Polymer reactions of the pendant bromide of the polyoxetanes were examined with several nucleophiles such as anions of carboxylates and alkoxides, and amines (Entries 19 in Table II). The degree of substitution was calculated on the basis of ${ }^{1} \mathrm{H}$ NMR spectroscopy and/or elemental analysis. Some functional groups of the product polymers were further converted to other groups. The structures of the product polymers were confirmed by their IR and/or ${ }^{1} \mathrm{H}$ NMR spectra as shown in Table III.

With Potassium Acetate. Poly(3a) was heated with powdered KOAc in toluene with efficient stirring under reflux. The product polymer 19 indicated a negative Beilstein test

Table III. Identification of modified polyethers

\begin{tabular}{|c|c|c|}
\hline Polymer & $\begin{array}{l}\text { Pendant } \\
\text { functional group }\end{array}$ & IR bands and ${ }^{1} \mathrm{H}$ NMR signals ${ }^{a}$ \\
\hline 19 & $\mathrm{CH}_{2} \mathrm{O}\left(\mathrm{CH}_{2}\right)_{4} \mathrm{OAc}$ & $1745,1245,1040 \mathrm{~cm}^{-1}$ (ester); $2.05\left(\mathrm{~s}, \mathrm{COCH}_{3}\right)$ \\
\hline $\operatorname{Poly}(15)$ & & $4.08 \mathrm{ppm}\left(\mathrm{t}-\mathrm{like}, \mathrm{CH}_{2} \mathrm{OAC}\right)$ \\
\hline \multirow[t]{2}{*}{20} & $\mathrm{CH}_{2} \mathrm{O}\left(\mathrm{CH}_{2}\right)_{4} \mathrm{OAc}$ & $1745,1245,1040$ (ester); 3060,3030,1600,1580,750,700 $\mathrm{cm}^{-1}$ (phenyl); \\
\hline & & $2.02\left(\mathrm{~s}, \mathrm{COCH}_{3}\right) ; 4.10\left(\mathrm{t}-\mathrm{like}, \mathrm{CH}_{2} \mathrm{OAc}\right) ; 7.27 \mathrm{ppm}(\mathrm{s} \text {-like, } \mathrm{ArH})^{\mathrm{b}}$ \\
\hline 21 & $\mathrm{CH}_{2} \mathrm{O}\left(\mathrm{CH}_{2}\right)_{4} \mathrm{OH}$ & $3350(\mathrm{OH}) ; 1060 \mathrm{~cm}^{-1}(\mathrm{C}-\mathrm{O}$ of primary alcohol $)$ \\
\hline 22 & $-\mathrm{CH}_{2} \mathrm{O}\left(\mathrm{CH}_{2}\right)_{4}-\mathrm{OCH}_{2} \mathrm{Ph}$ & $3060,3030,1585,1500,1485,755,700$ (phenyl); $1100 \mathrm{~cm}^{-1}$ (ester); \\
\hline Poly(16) & & $4.49\left(\mathrm{~s}, \mathrm{CH}_{2} \mathrm{Ph}\right) ; 7.32 \mathrm{ppm}(\mathrm{s}-\mathrm{like}, \mathrm{ArH})$ \\
\hline 23 & $\begin{array}{l}\mathrm{CH}_{2} \mathrm{O}\left(\mathrm{CH}_{2}\right)_{4} \mathrm{OCH}_{2}- \\
\mathrm{C}\left(\mathrm{CH}_{2} \mathrm{O}\right)_{2} \mathrm{C}\left(\mathrm{CH}_{3}\right)_{2} \\
\mathrm{CH}_{3}\end{array}$ & $1090,835 \mathrm{~cm}^{-1}$ (cyclic acetal); $1.3-1.4 \mathrm{ppm}\left(\mathrm{CH}_{3}\right.$ on acetal ring) \\
\hline & $\begin{array}{l}\mathrm{CH}_{2} \mathrm{O}\left(\mathrm{CH}_{2}\right)_{4} \mathrm{OCH}_{2}- \\
\mathrm{C}\left(\mathrm{CH}_{2} \mathrm{OH}\right)_{2} \\
\mathrm{CH}_{3}\end{array}$ & $3400(\mathrm{OH}) ; 1040 \mathrm{~cm}^{-1}(\mathrm{C}-\mathrm{O}$ of primary alcohol $)$ \\
\hline 25 & $\mathrm{CH}_{2} \mathrm{O}\left(\mathrm{CH}_{2}\right)_{4} \mathrm{NPh}$ & $1600,755,700 \mathrm{~cm}^{-1}\left(\right.$ phenyl) ${ }^{\mathrm{c}}$ \\
\hline \multirow{2}{*}{$\begin{array}{l}26 \\
27\end{array}$} & $\mathrm{CH}_{3}$ & \\
\hline & $\begin{array}{l}\mathrm{CH}_{2} \mathrm{O}\left(\mathrm{CH}_{2}\right)_{4}- \\
{ }^{+} \mathrm{NC}_{5} \mathrm{H}_{4}-\mathrm{CONH}_{2} \mathrm{Br}^{-}\end{array}$ & $3350,3200\left(\mathrm{NH}_{2}\right) ; 1690-1650 \mathrm{~cm}^{-1}(\mathrm{C}=\mathrm{O})^{\mathrm{d}}$ \\
\hline \multirow{2}{*}{$\begin{array}{l}29 \\
30 \\
31\end{array}$} & $-\mathrm{CH}_{2} \mathrm{C}_{6} \mathrm{H}_{4}-\mathrm{Br}, \mathrm{CH}_{2} \mathrm{Ph}$ & $840-850$ (para); $750-700 \mathrm{~cm}^{-1}$ (ortho, phenyl); $2.0-2.4$ (methine $\mathrm{CH}$ ); \\
\hline & & $2.5-3.0\left(\mathrm{CH}_{2} \mathrm{Ar}\right) ; 3.0-3.5\left(\mathrm{CH}_{2}\right.$ of main chain $) ; 7.1-7.5 \mathrm{ppm}(\mathrm{ArH})^{\mathrm{e}}$ \\
\hline 32 & $31]$ & $1520,1345\left(\mathrm{NO}_{2}\right) ; 855$ (para); $740,700 \mathrm{~cm}^{-1}$ (ortho, pheny \\
\hline 34 & $\mathrm{CH}_{2} \mathrm{C}_{6} \mathrm{H}_{4}-\mathrm{Ac}, \mathrm{CH}_{2} \mathrm{Ph}$ & $1670(\mathrm{C}=\mathrm{O}) ; 855($ para $) ; 730,700 \mathrm{~cm}^{-1}$ (ortho, phenyl) \\
\hline
\end{tabular}

a These are characteristic bands and signals for identifying product polymers.

b Also see the NMR spectrum in Figure 1.

c See Figure 2 for NMR spectrum of 26.

d See Figure 3 for NMR spectrum of 27.

e NMR signals for $\mathbf{3 0}$. 


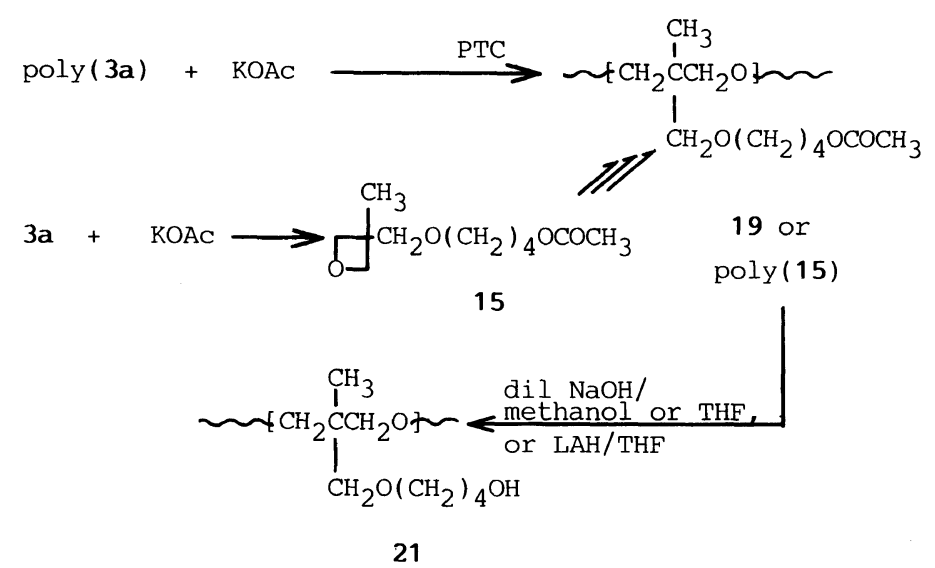

Scheme 3

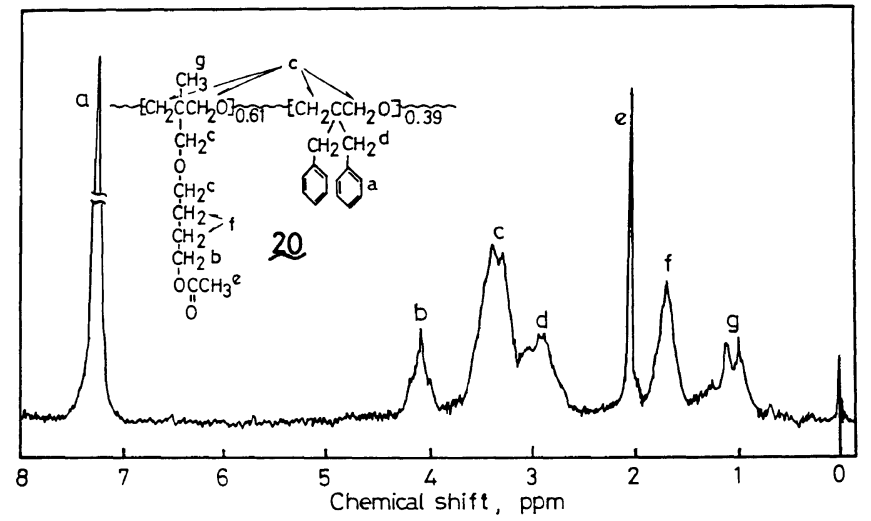

Figure 1. ${ }^{1} \mathrm{H}$ NMR spectrum of 20 in $\mathrm{CDCl}_{3}$.

and showed strong IR bands of the ester group. The polyoxetane with the pendant ester was also prepared by the other route via the cationic ring-opening polymerization of $\mathbf{1 5}$ which was synthesized from 3a and KOAc in benzene in the presence of TBAB. Poly(15) $\left(\bar{M}_{n} 1.6 \times 10^{4}\right)$ showed an IR spectrum identical with that of 19, and was soluble in ether, DCM, chloroform, benzene, and THF; these were also good solvents for $\mathbf{1 9}$. The bromine of poly (3a-co-7) was displaced by acetoxyl group under the same phase-transfer catalytic conditions as those to give 19 from poly(3a). An IR spectrum of $\mathbf{2 0}$ obtained from the reaction of poly(3a-co-7) with KOAc showed bands due to the ester group besides bands due to the monosubstituted aromatic ring. The ${ }^{1} \mathrm{H}$ NMR spectrum of $\mathbf{2 0}$ is shown in Figure 1. Signals (a) - (g) were correspondingly assigned to the respective protons of 20 . Signal (g) is due to the methyl group on the quaternary carbon of the polymer backbone and signal (a), to protons of the aromatic ring. An integral intensity ratio of signal (a) to signal $(\mathrm{g})$ is about $15: 8$, indicating that the mole fraction of the 7 unit in 20 is 0.36 . This value is approximately identical with the mole fraction for the 7 unit in the starting polymer, poly(3a-co-7), obtained from the monomers $\mathbf{3 a}$ and 7 fed at a charge ratio of $61: 39$. Furthermore, on the 
basis of an intensity ratio of $7.5: 15.0$ for signal (e) of the acetoxyl group toward signal (a) of the benzyl group, the mole fraction of 0.63 is calculated for the ester unit of 20 . These findiigs indicate that the pendant bromide was converted almost quantitatively into the acetoxyl group by the polymer reaction under phase-transfer catalytic conditions.

The pendant ester groups of 19 and poly(15) were hydrolyzed with $2.5 \mathrm{moll}^{-1} \mathrm{NaOH}$ in methanol or THF at reflux temperature to give the hydroxyl group of 21 . The product polymers after alkaline hydrolysis indicated distinct IR bands at 3350 and $1060 \mathrm{~cm}^{-1}(\mathrm{OH}$ and $\mathrm{C}-\mathrm{O}$ of primary alcohol, respectively), but no bands due to the ester group. 21 was soluble in methanol, ethanol, and THF, but not in ether, DCM, chloroform, benzene, and water. The pendant ester of poly(15-co-4a) was also converted to the hydroxyl group on the alkaline hydrolysis of the gel polymer, which was swollen in methanol or THF, over a somewhat prolonged reaction period. The acetoxyl group of poly(15) was reduced completely to the hydroxyl group of 21 with LAH in dry THF, although removing inorganic byproducts from the product polymer was considerably troublesome in the work-up. When the hydrolysis of poly(15) and 19 was carried out in toluene and $50 \% \mathrm{NaOH}$ at $50-100^{\circ} \mathrm{C}$ in the presence of tetrabutylammonium hydroxide, a product polymer was obtained in each case within a shorter reaction time, but was insoluble in all the solvents used above.
Formation of the gel polymer on the hydrolysis may be interpreted by the crosslinking reaction in which the alkoxide anion, formed at the polymer side chain-end by the hydrolysis of the ester, attacks the $\alpha$-methylene carbon adjacent to the unchanged pendant acetoxyl group to form the ether cross-linkage between the polymer backbones.

With Hydroxyl Compounds. The bromine atom of poly(3a) was converted to the benzyloxy group almost quantitatively by the phase-transfer catalytic reaction with benzyl alcohol (11). An IR spectrum of the product polymer 22 showed bands due to the monosubstituted aromatic ring at 3060, 3030, 1585, $1500,1485,755$, and $700 \mathrm{~cm}^{-1}$ besides a very weak band ascribed to $\mathrm{OH}$ stretching vibration at $3300 \mathrm{~cm}^{-1}$, but not bands due to olefin around $1630 \mathrm{~cm}^{-1}$. Thus, 22 has an aromatic ring covalently attached to the side chain, but is not contaminated with 11. In a ${ }^{1} \mathrm{H}$ NMR spectrum of 22, an integral intensity ratio of signals indicated that $\mathbf{2 2}$ was produced in the complete conversion of the bromine to the benzyl group. Furthermore, signals due to olefinic protons, formed by elimination reactions of the pendant alkyl bromide, was not detected; actually it has been found that signals due to the terminal olefinic protons of 3 (2-oxa-5-hexenyl)-3-methyloxetane appeared as complicated patterns in a region of 4.98 6.25 ppm. ${ }^{11}$ An authentic polymer $\left(\bar{M}_{n} 2200\right)$ for 22 was synthesized by the cationic ringopening polymerization of 3-(6-benzyloxy-2-
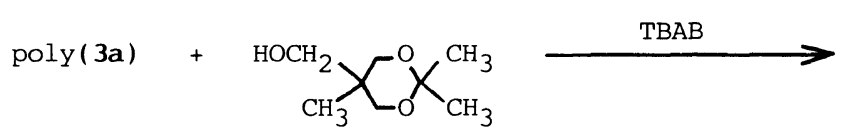

17

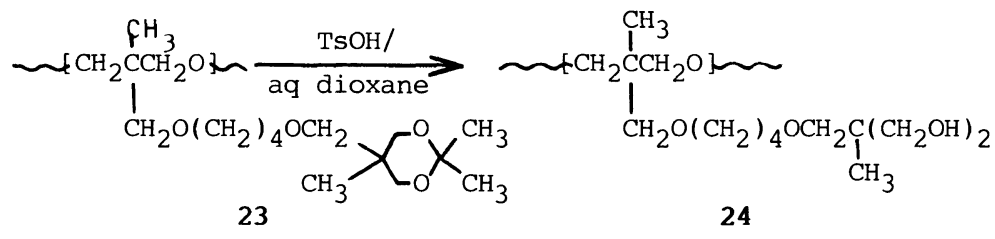

Scheme 4 
oxahexyl)-3-methyloxetane (16). The IR spectrum of 22 coincided with that of poly(16).

The hydroxyl group of cyclic acetal 17 also formed the ether linkage of $\mathbf{2 3}$ by reaction with the bromine of poly(3a) under phase-transfer catalytic conditions using TBAB as a PTC. In the spectrum of $\mathbf{2 3}$, formation of the pendant cyclic acetal of $\mathbf{2 3}$ was obvious on the basis of the very weak band at $3300 \mathrm{~cm}^{-1}$ and the distinct band due to the cyclic acetal linkage at 1090 and $835 \mathrm{~cm}^{-1}$. These bands of the cyclic acetal disappeared in the spectrum of $\mathbf{2 4}$, obtained by hydrolysis of $\mathbf{2 3}$ in $30 \%$ aqueous dioxane containing a catalytic amount of $p$ toluenesulfonic acid, while bands due to the resultant primary alcohol appeared at 3400 and $1040 \mathrm{~cm}^{-1}$. A model compound 18 for 23 also showed the bands due to the acetal ring at 1090 and $835 \mathrm{~cm}^{-1}$ in the IR spectrum resembling that of 23.

With Amines. Amination and quaternization reactions of the bromide of $\operatorname{poly}(3 \mathbf{3 a})$ were examined with aromtic and aliphatic amines. The reaction of poly(3a) with excess $N$ methylaniline (12) using $\mathrm{K}_{2} \mathrm{CO}_{3}$ as a $\mathrm{HBr}$ trapping base gave $\mathbf{2 5}$ having an aniline residual group at the side chain-end. 25 purified by reprecipitation using a chloroform-methanol system was swellable but insoluble in 2 to $6 \mathrm{~mol}^{-1}$ aqueous $\mathrm{HCl}$. The IR spectrum of $\mathbf{2 5}$ showed a strong absorption band characteristic of the aromatic ring of aniline de- rivatives at $1600 \mathrm{~cm}^{-1}$, while a very weak band due to $\mathrm{NH}$ stretching was detected at 3300 $\mathrm{cm}^{-1}$. The reaction of poly $(3 \mathbf{a}-\mathrm{co}-6)$ with $\mathbf{1 2}$ also took place on heating the reactants in DMF at $60^{\circ} \mathrm{C}$. A ${ }^{1} \mathrm{H}$ NMR spectrum of the product polymer $\mathbf{2 6}$ is shown in Figure 2. The protons $\left(H_{\mathrm{h}}\right.$ and $\left.H_{i}\right)$ of the methyl groups attached to the polymer backbone resonate in a region of 0.87 to $0.89 \mathrm{ppm}$ and the proton $\left(H_{\mathrm{f}}\right)$ of $N$-methyl group in the side chain does so at $2.92 \mathrm{ppm}$. From an integral intensity ratio of a total $16 \mathrm{H}$ for $H_{\mathrm{h}}$ and $H_{\mathrm{i}}$ toward $2 \mathrm{H}$ for $H_{\mathrm{f}}$, the degree of the amination reaction was calculated to be about 0.6. Reaction of poly(3a) with diisopropylamine in DMF gave a gel product remarkably swellable in chloroform and insoluble in the usual solvents. The diisopropylbutylamine moiety, formed by the reaction of the bromide of $\operatorname{poly}(\mathbf{3 a})$ with the aliphatic amine, seemed to be readily quaternized by the unchanged pendant bromide. However, the reaction of poly(3a) with $\mathbf{1 2}$ gave the tertiary aromatic amine not quaternizable with the unchanged pendant bromide, since quaternization of the aromatic amine formed is a disadvantageous reaction interrupting the $\mathrm{n}-\pi$ electron resonance system in an uniplanar aniline structure.

Nicotinamide (13) was also used for the quaternization of the pendant bromide by heating poly(3a) and 13 in DMF at $100^{\circ} \mathrm{C}$. The product polymer $\mathbf{2 7}$ became soluble in meth-

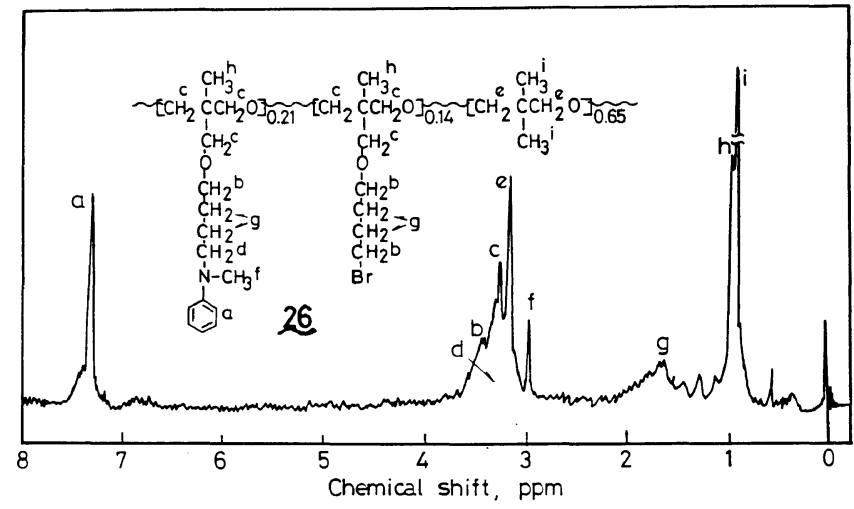

Figure 2. ${ }^{1} \mathrm{H}$ NMR spectrum of 26 in $\mathrm{CDCl}_{3}$. 


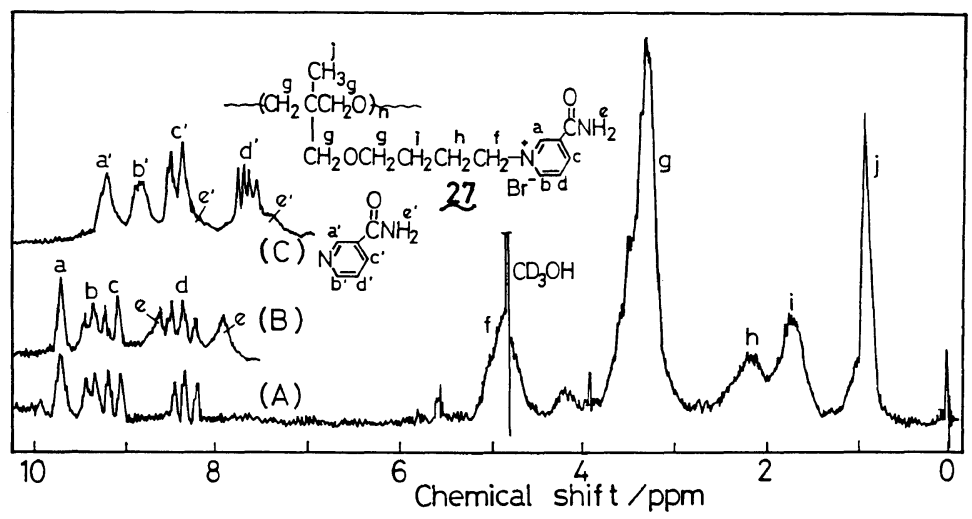

Figure 3. ${ }^{1} \mathrm{H}$ NMR spectra of (A) 27 in methanol- $d_{4}$ and (B) in methanol, and of (C) 13 in methanol. Spectra $(B)$ and $(C)$ are represented in a region of $7-10 \mathrm{ppm}$.

anol, a poor solvent for poly(3a). The ${ }^{1} \mathrm{H}$ NMR spectra of 27 in methanol- $d_{4}$ and undeuterated methanol are shown in Figures $3 \mathrm{~A}$ and $3 \mathrm{~B}$, respectively. Signals (a)-(d) are assigned to protons of the pyridinium ring of 27 , Every aromatic proton of $\mathbf{2 7}$ resonates in a lower field than the corresponding aromatic proton of 13 (Figure 3C). In the spectra of 27 (Figures $3 \mathrm{~A}$ and $3 \mathrm{~B}$ ), the signal due to $H_{\mathrm{d}}$ of the pyridine ring of $\mathbf{1 3}$ was not observed in $7.3-7.7 \mathrm{ppm}$, indicating that the product polymer is not contaminated with the unchanged 13. The signals of the amide protons disappear on treating them with deuterated methanol. Absence of the olefinic group in $\mathbf{2 7}$ is also obvious from the lack of signals correspondingly assignable at $4.98-6.25 \mathrm{ppm}$ (vide ante). The degree of functionalization in $\mathbf{2 7}$ was calculated to be about 1.0 on the basis of the intensity ratio of aromatic protons $\left(H_{\mathrm{a}-\mathrm{d}}\right)$ to the methyl proton $\left(H_{\mathrm{j}}\right)$. Furthermore, on the basis of nitrogen and bromine content in 27 , the complete conversion of the pendant bromide into the pyridinium bromide was also estimated, and the product polymer seemed to contain $14 \mathrm{wt} \%$ moisture, assuming water as the only contaminant. Reduction of the pyridinium bromide to the corresponding dihydropyridine in the polymer took place as soon as an aqueous $\mathrm{Na}_{2} \mathrm{~S}_{2} \mathrm{O}_{4}$ solution was added to 27 in methanol, depositing the product polymer quickly from the solution. The reduced polymer was insoluble in the usual solvents. In the IR spectra of the polymers before and after the reduction, a broad band of $\mathrm{C}=\mathrm{O}$ stretching of the amide group appeared in a region of $1690-1650 \mathrm{~cm}^{-1}$ before reduction and at $1680 \mathrm{~cm}^{-1}$ after reduction. Additionally, the reduced 27 showed new absorption bands at 1640 and $1550 \mathrm{~cm}^{-1}$, which were assigned to a nonaromatic $\mathrm{C}=\mathrm{C}$ bond of the dihydropyridine ring. Observation of the IR spectra in the reduction of 27 was compatible with that in the reduction of polystyrene-supported nicotinamides. $^{32}$

Furthermore, the quaternization of the pendant bromide in the polymer is understood on the basis of phase-transfer catalyzing abilities of 28a and $\mathbf{2 8 b}$ prepared, respectively, by the reaction of poly $(3 \mathbf{a}-c o-4 \mathbf{a})$ and poly $(3 \mathbf{b}-\mathrm{co}-\mathbf{4 a})$ with 14 in DMF at $100^{\circ} \mathrm{C}$. Of course, evidence for the formation of quaternized groups in these copolymers cannot be confirmed by their IR spectroscopy. Contents of the ammonio groups of 28a and $\mathbf{2 8 b}$ were calculated from nitrogen contents of the resultant polymers. The degree of functionalization $(k / x)$ was estimated on the basis of nitrogen and bromine content. Additionally, about $30 \mathrm{wt} \%$ moisture was also estimated as the only contaminant in 


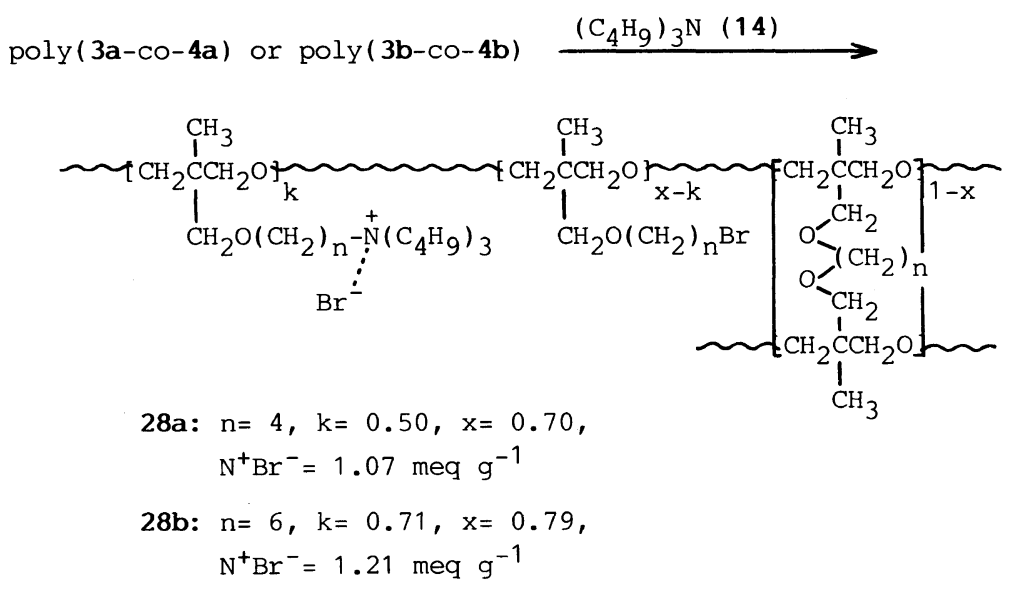

Scheme 5

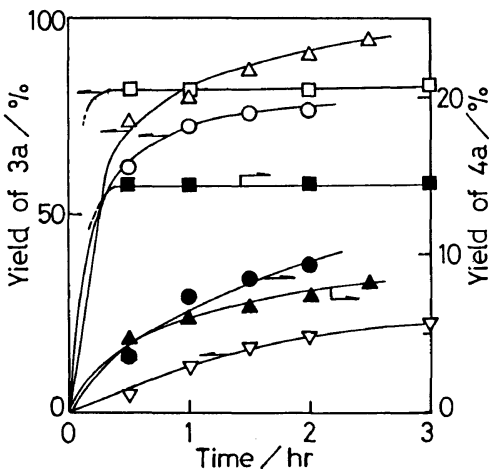

Figure 4. Time-yield curves for products $3 \mathbf{a}(O, \triangle$, $\square, \nabla)$ and $\mathbf{4 a}(\boldsymbol{O}, \boldsymbol{\Delta}, \mathbf{\square})$ in the reaction of $\mathbf{1}$ with $\mathbf{2 a}$ in the presence of the polymeric PTC: $(\bigcirc, \bigcirc) 28 a, 2.7 ;(\triangle$, A) $28 \mathbf{b}, 3.0 \mathrm{~mol} \%$ of the ammonium site to $1 ;(\square, \square)$ TBAB, $5 \mathrm{~mol}^{\circ} ;(\nabla)$ without PTC.

28a and 28b in the preceding manner (also see the footnote $c$ in Table II). The phase-transfer catalyzing abilities of $\mathbf{2 8 a}$ and $\mathbf{2 8 b}$ are demonstrated in the etherification reaction of $\mathbf{1}$ with $2 \mathbf{a}$ in hexane and a $50 \%$ aqueous $\mathrm{NaOH}$ solution (Figure 4). The presence of catalytic amounts of 28a and 28b was effective for facilitating the etherification reaction, compared with the results in the reaction without any catalyst. These findings obviously show that the pendant bromide of the polyoxetane resin is quaternized with the tertiary amine to yield the tetraalkylammonium bromide group at the side chain-end. Phase-transfer catalysis of polymeric PTCs has been further investigated in detail and described in another report. ${ }^{33}$

\section{Electrophilic Substitution of the Benzyl Group of the Polyoxetane}

The electrophilic substitution reactions of aromatic rings have been widely employed in the modification of polystyrenes. According to reported methods, typical reactions such as bromination, ${ }^{34}$ acylation, ${ }^{35}$ and nitration ${ }^{36}$ were examined for the benzyl group of each polymer from $7, \mathbf{8}$, and $\mathbf{9}$. The results are summarized in Entries $10-14$ in Table II. These products and their derivatives were also identified by IR and/or ${ }^{1} \mathrm{H}$ NMR spectroscopy (Table III).

Bromination in the Presence of $\mathrm{ZnCl}_{2}$. The aromatic rings of the poly(3-benzyloxetane)s were brominated with bromine in chloroform in the presence of $\mathrm{ZnCl}_{2}$. A model polymer, poly(10), was synthesized to be compared with brominated polymers with respect to IR spectra. Bands due to the para substitution appeared around $840-850 \mathrm{~cm}^{-1}$. Probably, bromination also occurred at the ortho position of the aromatic ring, an IR band due to the 1,2-disubstituted benzene of the product polymer appearing in a region of $750-700$ 
$\mathrm{cm}^{-1}$ together with bands of the monosubstituted benzene of the unreacted aromatic ring.

Nitration with $\mathrm{HNO}_{3}$ and Acetic Anhydride. Nitration of poly $(9)$ was examined with nitric acid/acetic anhydride in chloroform. Nitro groups of the product polymer $\mathbf{3 2}$ was indicated by IR bands at 1520 and $1345 \mathrm{~cm}^{-1}$. These bands disappeared in the IR spectra of the reduction products 33a and 33b. The reduced polymer 33a with a primary amino group, indicated by an IR band around 3400 $\mathrm{cm}^{-1}$, was obtained on reprecipitation using a chloroform-methanol system, and 33b with an ammonium chloride group, indicated by a band around $2600 \mathrm{~cm}^{-1}$, was precipitated by adding concd $\mathrm{HCl}$ to the concentrated filtrate which contained a lower-molecular-weight fraction.

Acylation in the Presence of $\mathrm{AlCl}_{3}$. Acetylation was examined in the Friedel-Crafts reaction of the aromatic ring of poly(7) with acetyl chloride. The acyl group of $\mathbf{3 4}$ was converted to the oxime group of $\mathbf{3 5}$ almost quantitatively, because an IR band due to the carbonyl group at $1670 \mathrm{~cm}^{-1}$ disappeared completely and bands due to the oxime appeared at 3300,1630 , and $980 \mathrm{~cm}^{-1}$ in the spectrum of 35.

The ether linkage of the polyethers tended to cleave under acidic conditions applied in the electrophilic reactions, resulting in some decrease in the molecular weight of the product polymer. A polymer-end formed by the ether cleavage was converted to halides or esters with the reagents used or generated during the reaction. The product obtained in the acylation reaction indicated IR bands assignable to carbonyl groups around $1720 \mathrm{~cm}^{-1}$, although these intensities were considerably weak. Therefore, the results of elemental analysis should be adopted to roughly estimate the degree of ring substitution. On the other hand, ether linkages of both main and side chains of the polyoxetanes are stable on the nucleophilic reactions under applied basic conditions. In fact, any decrease in molecular weight was not observed for poly[3-(alkoxymethyl)-3-methyloxetane]s after treatment with butyllithium in dry toluene or ether at room temperature.

Thus, it is demonstrated in this paper that the pendant bromides of the polyoxetanes are readily employed in several typical nucleophilic displacement reactions concerning the alkyl bromides. Information about the polymer reactions examined on the pendant bromides of the soluble polyoxetanes would be of assistance in guiding the functionalization work of insoluble cross-linked polyoxetane resins that will be chosen as new polymer supports with qualities different from those of the cross-linked polystyrenes used widely.

\section{REFERENCES}

1. Y. Imai, M. Kajiyama, S. Ogata, and M. Kakimoto, Polym. J., 16, 267 (1984).

2. N. Yui, T. Oomiyama, K. Sanui, and N. Ogata, Makromol. Chem., Rapid Commun., 5, 805 (1984).

3. N. Yui, K. Nojiura, K. Sanui, and N. Ogata, Polym. J., 7, 969 (1985).

4. T. Tashiro and Y. Shimura, J. Appl. Polym. Sci., 30, 985 (1985).

5. J. Smid, Angew. Chem. Int. Ed., 11, 112 (1972).

6. T. Higashimura, T. Nakamura, and S. Aoshima, Polym. Bull., 17, 389 (1987).

7. P. Gramain and Y. Frere, Makromol. Chem., 188, 593 (1987).

8. H. Becker, H.-W. Lucas, J. Maul, V. N. R. Pillai, H. Anzinger, and M. Mutter, Makromol. Chem., Rapid Commun., 3, 217 (1982).

9. M. Mutter, K.-H. Altmann, and J. Schmitt, Makromol. Chem., Rapid Commun., 6, 785 (1985).

10. D. J. Banister, M. Doyle, and D. R. Macfarlane, J. Polym. Sci., Polym. Lett. Ed., 23, 465 (1985).

11. M. Motoi, H. Suda, K. Shimamura, M. Takei, and S. Kanoh, Bull. Chem. Soc. Jpn., 61, 1653 (1988).

12. Y. Minoura, K. Shiina, and K. Yoshikawa, J. Polym. Sci., A-1, 5, 2843 (1967).

13. A. C. Farthing and R. J. W. Reynolds, J. Polym. Sci., 12, 503 (1954); J. Chem. Sci., 3648 (1955).

14. S. Kambara and M. Hatano, J. Polym. Sci., 27, 284 (1958).

15. L. C. Case and C. C. Todd, J. Polym. Sci., 58, 633 (1962).

16. K. E. Hardenstein, C. J. Murphy, R. B. Jones, L. H. Sperling, and G. E. Manser, J. Appl. Polym. Sci., 30, 2051 (1985).

17. E. L. Vandenberg, J. Polym. Sci., Polym. Chem. Ed., 23, 951 (1985). 
18. J. S. Shih and D. A. Tirrell, J. Polym. Sci., Polym. Chem. Ed., 22, 781 (1984).

19. J. S. Shih, J. F. Brandt, M. P. Zussman, and D. A. Tirrell, J. Polym. Sci., Polym. Chem. Ed., 20, 2983 (1982).

20. T. Iizawa, T. Nishikubo, M. Ichikawa, and Y. Sugawara, J. Polym. Sci., Polym. Chem. Ed., 23, 1893 (1985).

21. E. J. Corey and N. Raju, Tetrahedron Lett., 24, 5571 (1983).

22. J. B. Rose, J. Chem. Soc., 542 (1956).

23. L. C. Case and F. Shimoyer, U. S. 3006926 (1962) [Chem. Abstr., 56, 5934 (1962)].

24. R. C. Osthoff, C. A. Brown, and J. A. Hawkins, $J$. Am. Chem. Soc., 73, 5480 (1951).

25. N. Remoll and N. S. Newman, Org. Synth., Coll. Vol. 3, 502 (1955).

26. I. Vogel, J. Chem. Soc., 1019 (1928).

27. L. Schleich, Chem. Ber., 20, 439 (1987).

28. A. W. Dox and L. Yoder, J. Am. Chem. Soc., 44,
1144 (1922).

29. P. Picard, D. Leclercq, J.-P. Bats, and J. Moulines, Synthesis, 550 (1981)

30. S. Searles, D. G. Hummel, S. Nukina, and P. E. Throckmorton, J. Am. Chem. Soc., 82, 2928 (1960).

31. M. Bartok, B. Kozma, and N. I. Shuikin, Izv. Akad. Nauk SSSR, Ser. Khim., 1241 (1966) [Chem. Abstr., 65, 18545a (1966)].

32. Y. Kurusu, K. Nakajima, and M. Okawara, Kogyo Kagaku Zasshi, 71, 934 (1968).

33. M. Motoi, K. Shimamura, C. Shimamura, S. Muramoto, S. Kanoh, and H. Suda, Bull. Chem. Soc. $J p n$. , in press.

34. M. J. Farrall and J. M. Fréchet, J. Org. Chem., 41, 3877 (1976).

35. P. G. Pietta, P. F. Carallo, K. Takahashi, and G. R. Marshall, J. Org. Chem., 39, 44 (1974).

36. R. B. King and E. M. Sweet, J. Org. Chem., 44, 389 (1979). 